\title{
AN EVALUATION OF THE SOLAR AND WIND ENERGY IN THE SOUTH-EAST OF ROMANIA
}

\author{
Article DOI: https://doi.org/10.35219/mtd.2018.2.03 \\ Victoria CARANFIL, Eugen RUSU*, Florin ONEA \\ University “Dunarea de Jos" of Galati, Department of Mechanical Engineering \\ E-mail: victoria.caranfil@ugal.ro
}

\begin{abstract}
The objective of the present work is to estimate the benefits which may be obtained from the implementation of a solar and wind project, by considering several reference sites, located in the southeastern part of Romania. In the first case study, the attractiveness of the solar energy will be evaluated for a production factory located in the vicinity of Galati city. The seasonal and annual fluctuation of solar energy will be discussed, by taking also into account the performances of a photovoltaic panel, which may be installed on the roof of these production halls. As for the second case study, the performances of some state-of-the-art wind turbines will be evaluated by taking into account three sites located along the Romanian shoreline, namely Sf. Gheorghe, Navodari and Vama Veche, respectively. According to these results, it was noticed that the photovoltaic panels will partially cover the energy demand for the selected factory, while in the case of wind energy, a single wind turbine defined by a rated capacity of $3 \mathrm{MW}$ seems to easily cover the local electricity budget, reported in Sf. Gheorghe and Vama Veche.
\end{abstract}

Keywords: Romania, solar energy, wind turbine, coastal environment, reanalysis data

\section{INTRODUCTION}

From all the renewable sources, the solar and wind energy are the most abundant and sustainable, being already extracted on a global scale throughout different technological systems [1], [2].

Regarding the solar radiation, it is estimated that almost 885 million tera watt hours (TWh) reach the earth surface each year, which can cover by 6200 times the energy demand reported for 2008, and by 4200 times the electricity consumption estimated for the year 2035. The solar irradiative energy can be easily converted into heat, while the flux of electromagnetic particles can be transformed into electricity throughout photovoltaic (PV) system [3]. As for the European Union, a significant percentage of the PV projects are located in France, United Kingdom, Spain, Italy and Germany. Regarding the annual growth rate (\%), this was located around 59\% for the interval 2005-2014, $14 \%$ for 2013-2014, while a small decrease of $2 \%$ seems to be reported for 2014-2020 [4].

By looking at the European generation mix, one may notice that there is interest in the solar and wind energy. In 2016, the solar sector reported a share of $3.4 \%$ as compared to $9.5 \%$ for wind, while, at the end of the year 2017, these values reached a maximum of $3.7 \%$ and $11.2 \%$, respectively [5]. The wind sector is a mature industry, which seems to dominate the renewable energy market. During the time, this sector was continually improved, being possible during these days to install generators in various environments, which may include artic or offshore regions [6,7]. Romania is located in a geographical area defined by important wind resources (both onshore and offshore), which can be considered suitable for the electricity production [8-10].

Taking all the above presented aspects into account, the purpose of this work is to assess the performances of some renewable systems, which may operate in various sites from the southeastern part of Romania.

\section{MATERIALS AND METHODS}

\subsection{Case study 1 - solar power}

First, the photovoltaic technology will be discussed and the electricity generated on the surface of an existing production factory of the company Grande Gloria LTD. Industrial halls are single floor structures and they maintain a relatively high roof-tofloor ratio, but also a big surface, in this case, they have a total surface of $8404 \mathrm{~m}^{2}$ (4 halls x $2101 \mathrm{~m}^{2}$ per each).

The company was founded in 1993, in Galati, Romania. The production started with a converting paper machine. In 2006, another factory was opened, 
the wet wipes line, which is actually the plant with the biggest capacity of production in Romania. After 3 years, it started the production for cosmetics and household liquid products. The fourth factory for blowing bottles, opened in 2010 in order to optimize the costs for the finished liquid products, and it was purchased a polyethylene terephthalate (PET) and high density polyethylene (HDPE) bottle blowing machine and, on 2012, it was opened the 5th factory for wet cloth and sponge converting. More details about these reference sites can be obtained from Fig. 1 , where it is indicated with $\mathrm{A} 1$ the position of this site (Galati, Vanatori village $-45.5^{\circ} \mathrm{N} / 28.02^{\circ} \mathrm{E}$ ). The solar radiation data are being provided by NASA (National Aeronautics and Space Administration) and cover the time interval from 1.01.1995 to 31.12.2005 [11]. Two parameters were considered for evaluation, namely: ALLSKY - all sky insolation incident on a horizontal surface $\left(\mathrm{kWhr} / \mathrm{m}^{2}\right)$; CLRSKY - clear sky insolation incident on a horizontal surface $\left(\mathrm{kWhr} / \mathrm{m}^{2}\right)$ [12]. The first parameter includes all the values, while for the second only the data having an average cloud cover less than $10 \%$ during a given day, averaged for that month.

The solar energy output reported by a photovoltaic system can be estimated by using the following equation [13]:

$$
E=A \cdot r \cdot H \cdot P R
$$

where, $E$ - energy (kWh); $A$ - total solar panel area, $\left(\mathrm{m}^{2}\right) ; r$ - solar panel yield; $H$ - the annual average irradiation on panels; $P R$ - the performance ratio.

\subsection{Case study 2 - wind power}

The sites considered for the wind assessment are located along the Romanian coastal areas, being defined close to Sf. Gheorghe (site B1), Navodari (site B2) and Vama Veche (site B3), as it can be observed from Fig. 1. The wind speed (reported at 10 $m$ height above sea surface) corresponds to the ERAInterim database, which are freely available for download [14].

Three wind turbines were considered for evaluation, namely V90-3.0MW [15], Areva M5000116 [16] and Senvion 6.2M126 [17], the power curves of these generators are being presented in Fig. 2. Since most of the turbines operate at a hub height of at least $80 \mathrm{~m}$, the initial ERA-Interim wind conditions were adjusted to this reference level throughout a logarithmic law [18-20]. For this work, the time interval located between 1.01.1998 and 31.12.2017 will be considered for evaluation.

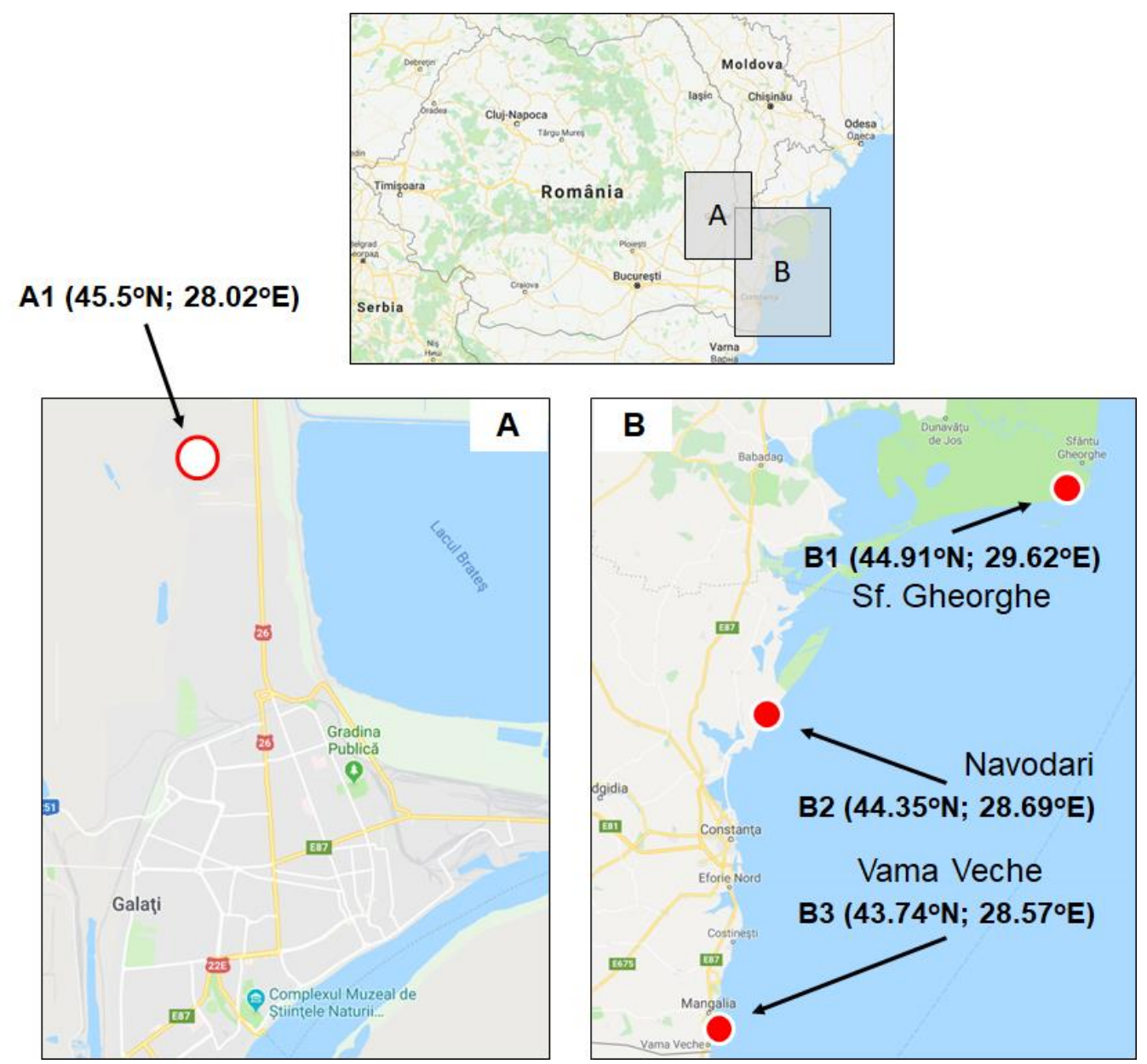

Fig. 1. Target areas considered for assessment, where: A - solar energy; B - wind energy 


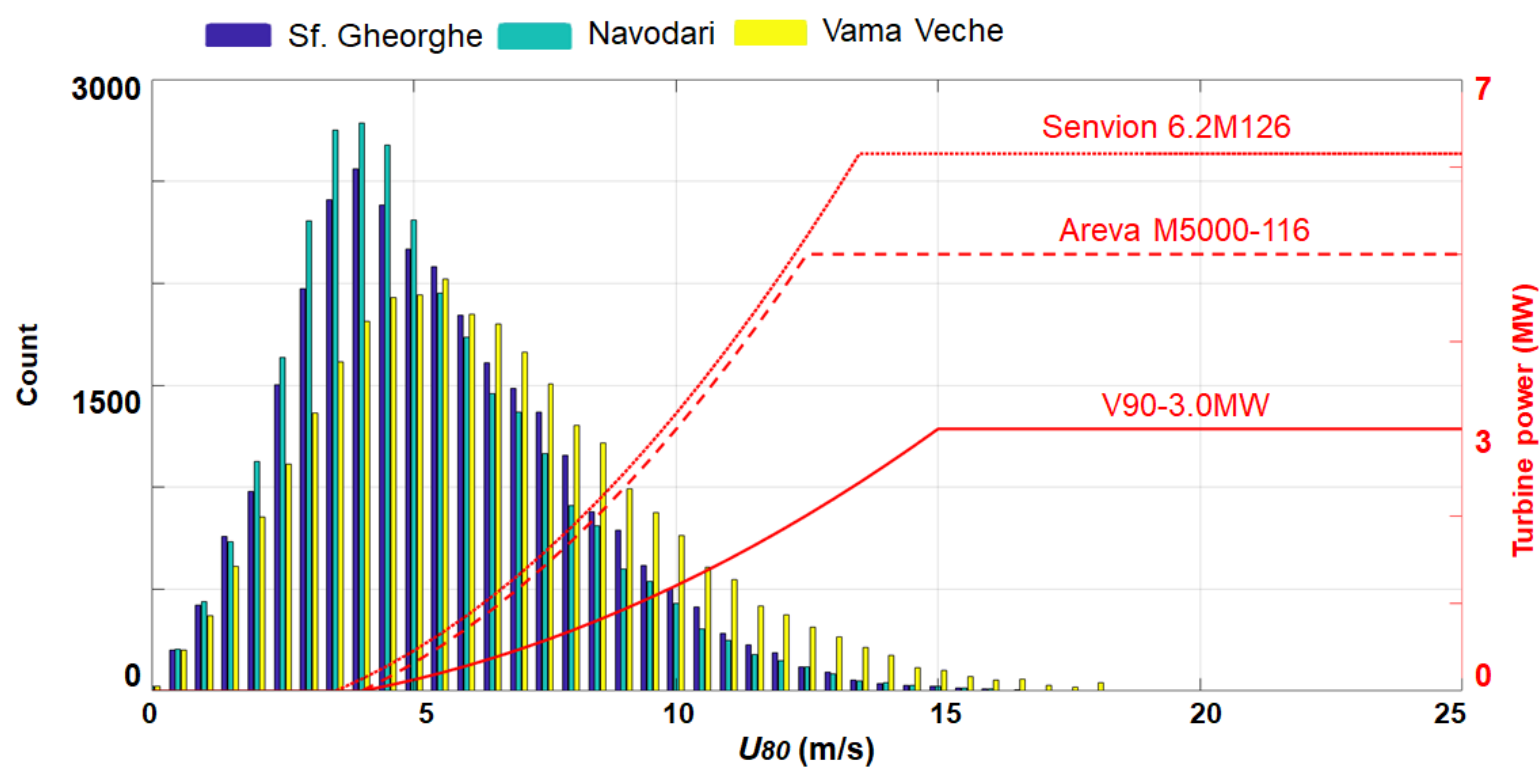

Fig. 2. Wind histograms and the turbine power curves

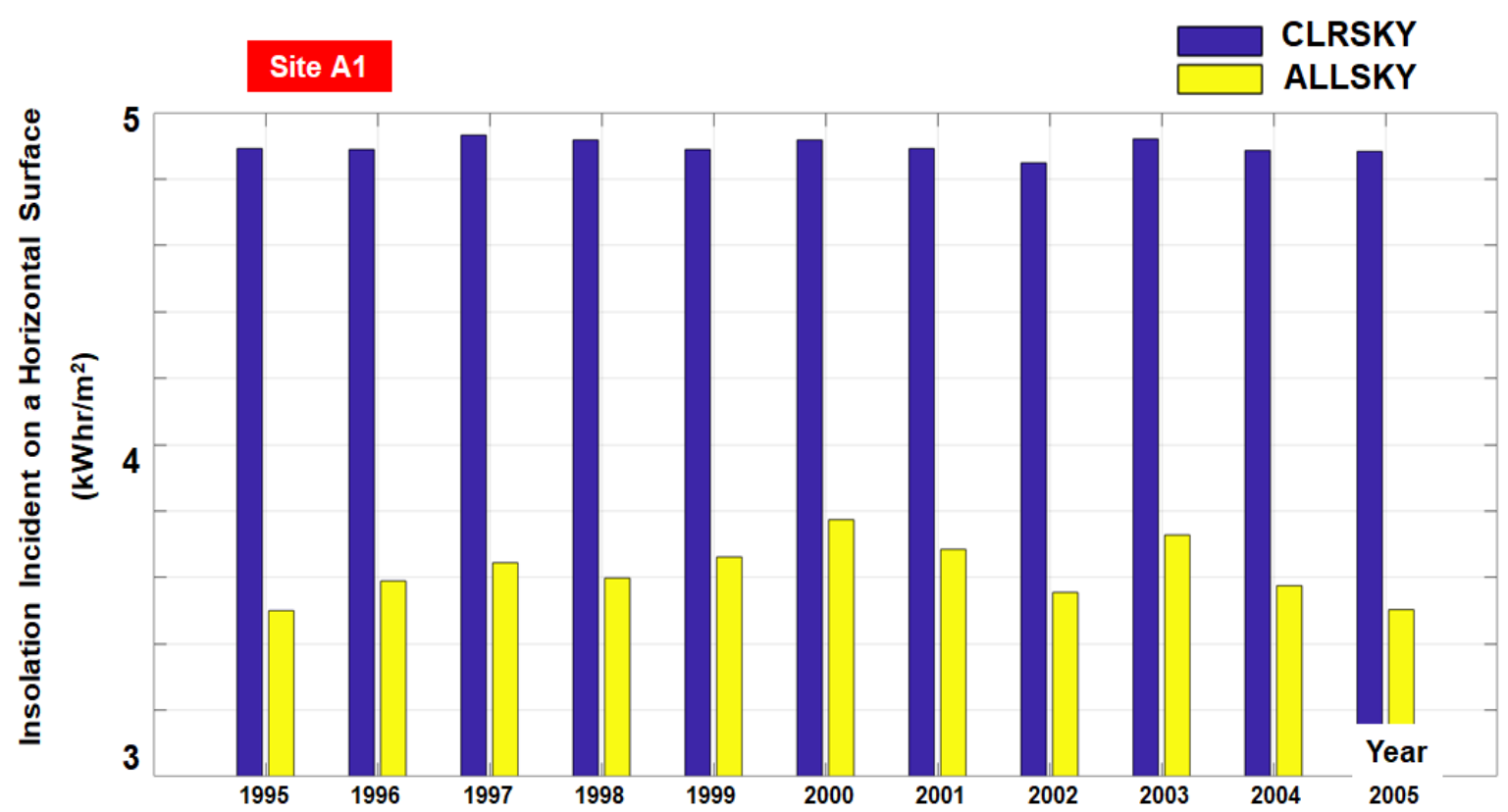

Fig. 3. Annual evolution of the solar insolation (mean values) reported for the site A1 (Vanatori, Galati)

\section{RESULTS}

Figure 3 illustrates the annual variation of the solar insolation, indicated for the CLRSKY and ALLSKY parameters. The first parameter shows much higher value, indicating values around the 4.9 $\mathrm{kWhr} / \mathrm{m}^{2}$ threshold, while, in the case of the ALLSKY, the reported results are not exceeding 3.8 $\mathrm{kWhr} / \mathrm{m}^{2}$. On a inter-annual scale, one may notice smaller variations, during the year 2005, being reported a minimum of $3.502 \mathrm{kWhr} / \mathrm{m}^{2}$.

The seasonal variation of the solar energy is presented in Fig. 4, where the values were grouped around four dominant intervals: Winter - December, January, February; Spring - March, April, May; Summer - June, July, August; Autumn - September, October, November. As expected, more important results are being noticed during the Spring and Summer period, reporting a maximum of 6.98 $\mathrm{kWhr} / \mathrm{m}^{2}$ for the CLRSKY data and $5.8 \mathrm{kWhr} / \mathrm{m}^{2}$ for the ALLSKY parameter. In this case, a minimum of $1.61 \mathrm{kWhr} / \mathrm{m}^{2}$ seems to be representative of the winter season.

As for the monthly variation, according to the values presented in Fig. 4, one may observe that the best a PV project will report much better results in May and June, while on the opposite end it was found December with a minimum of $1.1 \mathrm{kWhr} / \mathrm{m}^{2}$ indicated for ALLSKY data. The CLRSKY values are located in the interval $1.9 \mathrm{kWhr} / \mathrm{m}^{2}$ and 7.6 $\mathrm{kWhr} / \mathrm{m}^{2}$, while in the case of ALLSKY it may be expected a maximum of $6.1 \mathrm{kWhr} / \mathrm{m}^{2}$. 


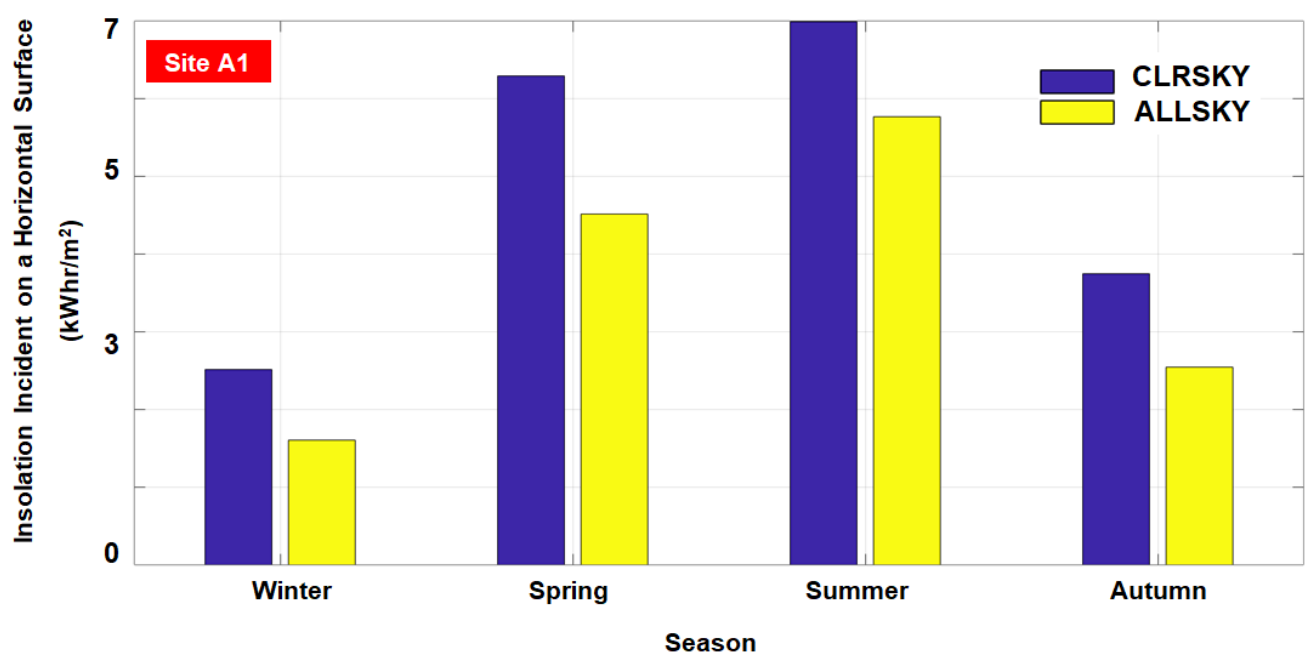

Fig. 4. Seasonal variation of the solar insolation (mean values) reported for the site A1.

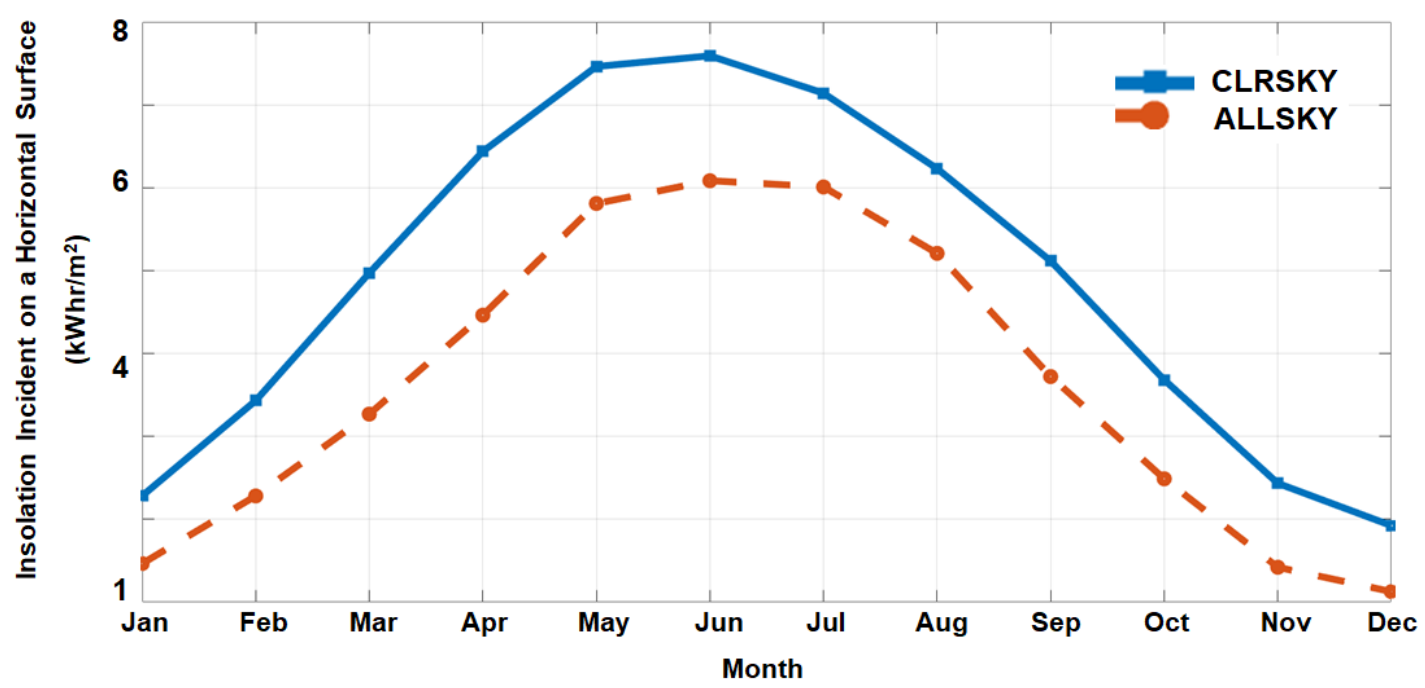

Fig. 5. The monthly variation of the solar insolation (mean values) reported for the site A1

Figure 6 illustrates the theoretical performances reported by a theoretical PV project (left legend), which may operate on the roof of the Grande Gloria Factory, by taking into account only the CLRSKY dataset. In this way, it will be estimated the best performances, which may be obtained from such a project and location. One may observe that the electricity demand (right, legend) for this factory is much higher during September-April, which correspond to a moderate solar radiation.

In terms of the electricity share covered by the $\mathrm{PV}$ project, it may be expected values in the range of 4.82\% and 8.2\% during April and September, while values located close to $2 \%$ may be reported during December and January.

Going to the wind energy, Figure 7 presents the Annual Energy Production (AEP) reported for each turbine and also the Capacity Factor (CF), which is the ratio between the power output and the rated capacity. The electricity output was estimated by using the power curve of each system and the wind distribution associated with each site [21].
As already noticed from the wind histograms presented in Fig. 2, the site Vama Veche seems to reveal more consistent wind resources, which are also reflected in the turbine performances. A maximum of $12 \mathrm{MWh}$ may be expected from the Senvion turbine, while a minimum of $2.5 \mathrm{MWh}$ is accounted by V90-3.0MW in the case of the Navodari site. The CF index reveals values in the interval $9.6 \%$ and $24.3 \%$, with the mention that the system Areva M5000 (5 MW) reveals a better efficiency than Senvion 6.2M126 (6.2 MW).

Table 1 presents a general picture of the estimated energy consumption at the site Sf. Gheorghe, Navodari and Vama Veche, indicating, in the same time, the share covered by a single turbine.

The data related to the population distribution was taken from the public domain, while the electricity consumption in Romania was estimated to be around 48.28 billion $\mathrm{kWh}$ (2015 estimation) reported to a total population of $21,529,967$ (July 2017 estimation.) [22]. 
(a)
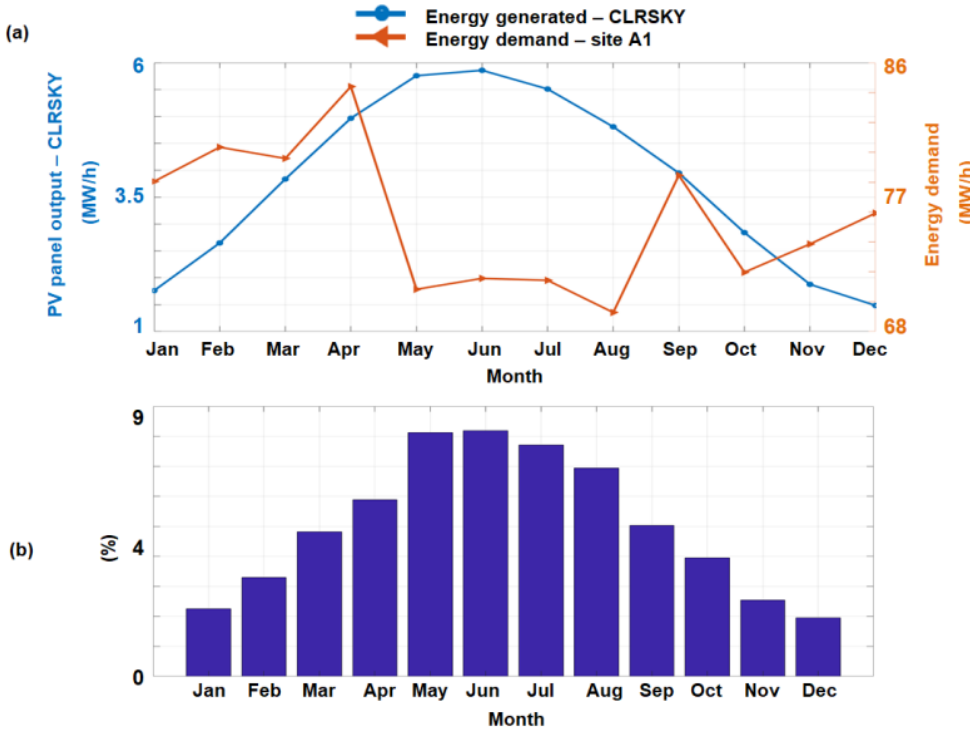

Fig. 6. Performance of a theoretical panel, which may be, installed on the roof of the Grande Gloria LTD. Industrial halls. The results are indicated in terms of: (a) monthly electricity demand of the factory and energy generated by a PV project; (b) electricity demand covered by the PV project

(a)

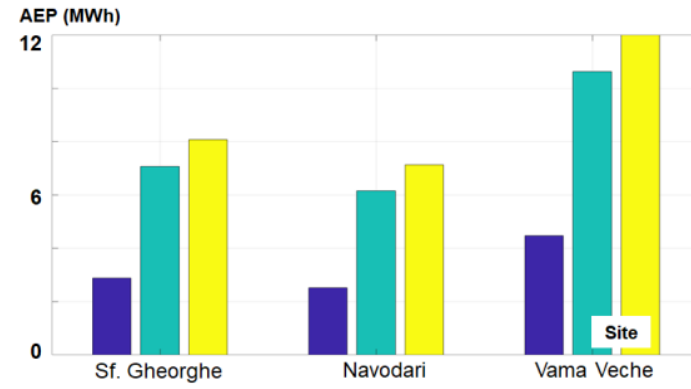

(b) $\quad \mathrm{CF}(\%)$

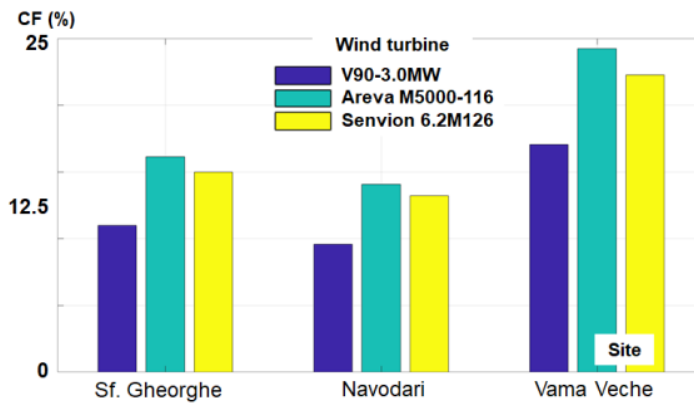

Figure 7. The performance of the wind turbines which may operate in the vicinity of Sf. Gheorghe, Navodari and Vama Veche.

Table 1. Electricity demand and turbine performances reported for the reference sites

\begin{tabular}{|c|c|c|c|c|}
\hline \multicolumn{3}{|c|}{ Population } & \multicolumn{2}{|c|}{ Electricity consumption (MWh) } \\
\hline \multicolumn{2}{|c|}{ Sf. Gheorghe } & 797 & Sf. Gheorghe & 1787 \\
\hline \multicolumn{2}{|l|}{ Navodari } & 31554 & Navodari & 7075 \\
\hline \multicolumn{2}{|l|}{ Vama Veche } & 178 & Vama Veche & 399 \\
\hline \multicolumn{3}{|c|}{ Turbine output (MWh) } & \multicolumn{2}{|c|}{ Share from turbines $(\%)$} \\
\hline \multirow{3}{*}{ Sf. Gheorghe } & V90-3.0MW & 2885 & \multirow{3}{*}{ Sf. Gheorghe } & 161 \\
\hline & Areva M5000 & 7062 & & 395 \\
\hline & Senvion $6.2 \mathrm{M} 126$ & 8082 & & 452 \\
\hline \multirow{3}{*}{ Navodari } & V90-3.0MW & 2520 & \multirow{3}{*}{ Navodari } & 3.56 \\
\hline & Areva M5000 & 6161 & & 8.7 \\
\hline & Senvion $6.2 \mathrm{M} 126$ & 7126 & & 10.07 \\
\hline \multirow{3}{*}{ Vama Veche } & V90-3.0MW & 4481 & \multirow{3}{*}{ Vama Veche } & 1122 \\
\hline & Areva M5000 & 10618 & & 2660 \\
\hline & Senvion 6.2M126 & 11997 & & 3005 \\
\hline
\end{tabular}

According to this estimation, Navodari, with 31554 inhabitants, requires approximately 7075 MWh, while the other sites reveal much lower value of 1787 MWh (Sf. Gheorghe) and 399 MWh (Vama Veche). The energy demand is easily covered by the turbines for the sites Sf. Gheorghe and Vama Veche, which are remote areas, mostly known for the tourism activities, while for the Navodari site, a maximum $10 \%$ is covered by Senvion generator.

\section{CONCLUSIONS}

In the present work, it was provided a general perspective of the benefits which may be obtained from the implementation of several renewable projects, which may be developed in the southeastern part of Romania.

Since more important solar resources seem to be reported in the Moldova-Dobrogea area, a first 
objective was to estimate the performance of PV for a factory operating in the vicinity of Galati. The results indicate that such a project operating on the roof of this factory, will not cover the industrial demand for electricity, in particular during the winter time when the sun radiation is much lower. The reported results indicate the best scenario (Clear sky data) while in the case of ALLSKY values, which include cloud cover, the expected result may significantly decrease.

As for the case studies involving wind turbines, was noticed that the southern part of the Romanian coastal area reveals a more attractive wind climate. Some state-of-the-art wind generators were considered, but for the Sf. Gheorghe and Vama Veche they reveal much higher value than the energy demand, which indicated that, probably, it will be more realistic to consider for implementation wind systems defined by much lower rated capacity. Going to Navodari site, the authors notice that for this site a wind farm configuration will be more suitable for implementation, taking into account that this site seems to reveal the lowest wind energy potential of this coastal area.

Finally, the authors mention that the potential of the natural sources from the southeastern part of Romania cannot be ignored, the proof being the continuously expanding of the renewable market on this region.

\section{ACKNOLEDGMENT}

This work was carried out in the framework of the research project REMARC (Renewable Energy extraction in MARine environment and its Coastal impact), supported by the Romanian Executive Agency for Higher Education, Research, Development and Innovation Funding - UEFISCDI, grant number PN-III-P4-IDPCE-2016-0017. The solar and wind data used in this study have been obtained from the NASA and ECMWF data server.

\section{REFERENCES}

[1] Raileanu A, Onea F, Rusu E. Evaluation of the Offshore Wind Resources in the European Seas Based on Satellite Measurements. Energy and Clean Technologies, Sofia: Stef92 Technology Ltd; 2015, p. 227-34.

[2] Ganea D, Amortila V, Mereuta E, Rusu E. A Joint Evaluation of the Wind and Wave Energy Resources Close to the Greek Islands. Sustainability 2017;9:1025. doi:10.3390/su9061025.

[3] Solar Energy Perspectives. IEA Webstore n.d. https://webstore.iea.org/solar-energy-perspectives (accessed July 29, 2018).

[4] Renewable energy in Europe 2017: recent growth and knock-on effects. European Environment Agency n.d. https://www.eea.europa.eu/publications/renewable-energyin-europe-2017 (accessed July 29, 2018).
[5] *** Publications 2018. https://www.agoraenergiewende.de/en/publications/the-european-powersector-in-2017-1/ (accessed July 29, 2018).

[6] Raileanu A, Onea F, Rusu E., 2015, Assessment of the wind energy potential in the coastal environment of two enclosed seas, New York, IEEE.

[7] Rusu E, Onea F., 2017, Joint Evaluation of the Wave and Offshore Wind Energy Resources in the Developing Countries. Energies, vol. 10, p. 1866.

[8] Niculescu D., Rusu E., 2016, Study of the wind regime in the north western part of the Black Sea, Mechanical Testing \& Diagnosis, vol. 6, pp. 25-34.

[9] Raileanu A, Onea F, Ivan A., Rusu E., 2016, Evaluation of the offshore wind energy potential in the Romanian co astal environment of the Black Sea, Marines Researches, pp. 5-18.

[10] Onea F, Rusu E. Efficiency assessments for some state of the art wind turbines in the coastal environments of the Black and the Caspian seas. Energy Explor Exploit 2016;34:217-34. doi:10.1177/0144598716629872.

[11] *** Solar radiation. MY NASA DATA, https://mynasadata.larc.nasa.gov/glossary/solar-radiation-2/ (accessed July 29, 2018).

[12] *** API Documentation, NASA POWER n.d. https://power.larc.nasa.gov/docs/v1/ (accessed July 29, 2018).

[13] *** How to calculate the output energy or power of a solar photovoltaic system, Excel PV calculator to estimate solar electricity output. n.d. https://photovoltaicsoftware.com/PV-solar-energy-calculation.php (accessed July 29, 2018).

[14] *** the European Centre for Medium-Range Weather Forecasts (ECMWF), https://www.ecmwf.int/ (accessed July 29, 2018).

[15] *** Vestas V90-3.0 - 3,00 MW - Wind turbine n.d. https://en.wind-turbine-models.com/turbines/603-vestasv90-3.0 (accessed July 29, 2018).

[16] *** AREVA M5000-116 - 5,00 MW - Wind turbine n.d. https://en.wind-turbine-models.com/turbines/23-arevam5000-116 (accessed July 29, 2018).

[17] *** Senvion 6.2M126 Offshore - 6,15 MW - Wind turbine, https://en.wind-turbine-models.com/turbines/885senvion-6.2m126-offshore (accessed July 29, 2018).

[18] Onea F, Eugen R., 2012, Evaluation of the wind energy resources in the Black Sea Area, Recent Researches in Environment, Energy Systems and Sustainability: 8th WSEAS International Conference on Energy, Environment, Ecosystems and Sustainable Development (EEESD '12), , p. 26-32.

[19] Onea F., Ciortan S., Rusu E., 2017, Assessment of the potential for developing combined wind-wave projects in the European nearshore, Energy Environ., vol. 28, pp. 580-97.

[20] Onea F., Raileanu A., Rusu E., 2016, Analysis of extreme wind and wave conditions in the black Sea, as reflected by the altimeter measurements, Mechanical Testing and Diagnosis, vol. 1, pp. 5-12.

[21] Ali S, Lee S-M, Jang C-M., 2017, Techno-economic assessment of wind energy potential at three locations in South Korea using long-term measured wind data, Energies, vol. 10, p. 1442.

[22] The World Factbook - Central Intelligence Agency, (on line) https://www.cia.gov/library/publications/theworld-factbook/geos/ro.html (accessed June 14, 2018). 